\title{
Foetal Kidney Development and Amniotic Fluid Formation in Upper Egyptian Pregnancies
}

\author{
MANAL M.S. EL-MELIGY, M.D.*; RENEAH R. BUSHRA, M.D.*; HAYAM Z. THABET, M.D.**; \\ NAGWA M. GHANDOUR, M.D.** and MAHMMOUD A. ABD EL-ALEEM, M.D.*** \\ The Departments of Human Anatomy \& Embryology*, Forensic Medicine \& Clinical Toxicology** and Obstetrics \& Gynecology***, \\ Faculty of Medicine, Assiut University, Egypt
}

\begin{abstract}
Background: The foetal kidney development is important for its normal function. The Amniotic Fluid Index (AFI) is used to assess the amniotic fluid volume. The main source of the amniotic fluid is the foetal urine.

Aim of the Work: To establish reference values for the foetal kidney length and the AFI throughout the second and third trimesters of the normal Upper Egyptian pregnancies and to clarify the correlations between these measurements.

Subject and Methods: An ultrasonographic examination was performed to measure the foetal kidney length and the AFI on 232 normal pregnant women from the 14 th week to the $42 \mathrm{nd}$ week of gestation. The correlations between the measurements were analysed statistically.

Results: The foetal kidney length increased gradually with gestation. There was a significantly positive correlation between the foetal kidney length and the gestational age. The linear regression showed that the gestational age could be assessed by using the foetal kidney length with an accuracy of \pm 1.078 week. From the 14 th week, the AFI increased progressively until the 24 th week. There was a positive correlation between the AFI and the gestational age and between the AFI and the foetal kidney length. From the $25^{\text {th }}$ week to the $32^{\text {nd }}$ week, the AFI demonstrated little variations. From the $33^{\text {rd }}$ week, the AFI declined gradually. There was a negative correlation between the AFI and the gestational age and between the AFI and the foetal kidney length.

Conclusion: The present study introduces reference values for both the foetal kidney length and the AFI in the normal Upper Egyptian pregnancies. It also discusses the correlation between the foetal kidney length and the AFI as early as the second trimester of pregnancy. At first, it is a direct correlation. Then, it shows minimal variations. Finally, it becomes an inverse one. The obtained information could be usefully applied clinically.
\end{abstract}

Key Words: Ultrasonography - Foetal Kidney length - Amniotic fluid index.

Correspondence to: Dr. Reneah R. Bushra, E-Mail: yosteena.atef2000@gmail.com

\section{Introduction}

THE normal foetal kidney development is crucial to the neonatal outcome [1]. Ahmadi et al., [2] stated that a standard nomogram of the foetal kidney length was useful to evaluate the growth disorders of the foetal kidneys in order to identify and manage any foetal renal abnormalities early.

The kidney develops from the uretric bud and the metanephric mesoderm. It begins to form at the 7 th week becoming functional at the $11^{\text {th }}$ week of gestation [3].

The development of the diagnostic ultrasound opened new possibilities for a more confident assessment of dating as reported by Butt and Lim [4] and Saxena et al., [5]. During the first trimester, the kidneys appear as hyperechoic oval structures on both sides of the developing vertebral column. Their echogenicity decreases gradually with aging $[6,7]$

The foetal kidney length is one of the nontraditional and more accurate pearls of the Gestational Age (GA) determination than other parameters like the Biparietal Diameter (BPD), Femur Length (FL), Head Circumference (HC) and Abdominal Circumference (AC) after the 24 th week of gestation $[\mathbf{8 , 9}$.

The amniotic fluid is a clear or little yellow liquid surrounds the foetus [10]. It promotes the musculo-skeletal development and allows for an easier foetal movement [11]. Any decrease or increase in the volume of the amniotic fluid leads to pregnancy complications [12].

Underwood et al., [13] stated that the assessment of the amniotic fluid was a complementary part of 
the ultrasonographic report of the pregnant female. Borges et al., [14] reported that the AFI was a semiquantitative technique used to evaluate the Amniotic Fluid Volume (AFV) within the gravid uterus. It was measured against the AFI chart. The AFI could be a useful adjunct to other foetal biometrics, to identify adverse outcomes [15].

The amniotic fluid appears constantly during the second half of pregnancy. The main source of its production is the baby's urine $(700 \mathrm{ml} /$ day $)$ and lung secretions ( $350 \mathrm{ml} / \mathrm{day})$. Its clearance is mainly by the baby swallowing and passing it back into the placental circulation [16]. Oligohydramniosis defined as an AFI of $\leq 5 \mathrm{~cm}$ [11], and polyhydramnios as either an AFI $\geq 25 \mathrm{~cm}$ or a maximum vertical pocket $\geq 8 \mathrm{~cm}$ even in the presence of an AFI $<25 \mathrm{~cm}$ [17].

Patrelli et al., [18] stated that a balance was required to maintain a healthy $\mathrm{AFV}$. It was influenced by hormones like prolactin and prostaglandins, the osmotic and hydrostatic forces, the maternal hydration and the baby's well-being.

The aim of this study was to establish the foetal kidney length and AFI scales and their correlations throughout the second and third trimesters of the normal Upper Egyptian pregnancies.

\section{Subjects and Methods}

A cross-sectional study was done on 232 healthy Upper Egyptian pregnant women who were following-up their pregnancy at the Department of Obstetrics and Gynecology, Assiut University Hospital between 2015 and 2017. They were between 18 and 40 years old of a mean age of 29.3 years. Each had a singleton foetus between 14 and 42 weeks of gestation. The mothers were sure of

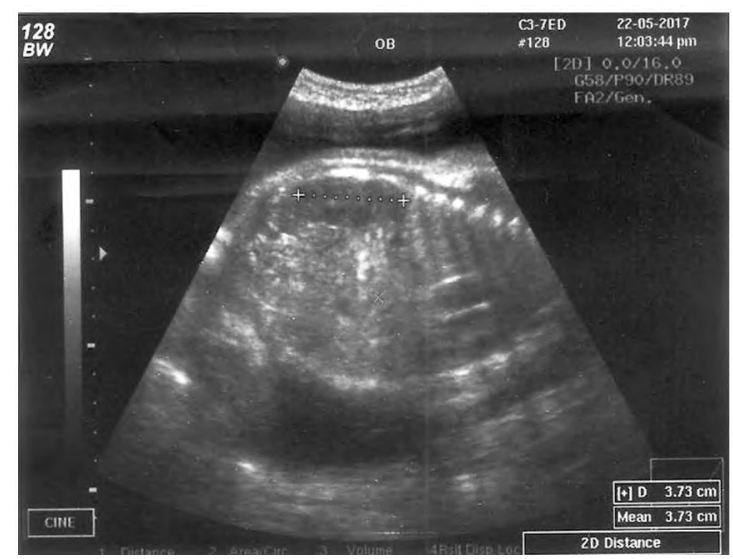

Fig. (1): An ultrasonographic image showing the maximal longitudinal renal axis. Notice that the two calipers are positioned in relation to the upper and lower poles of the kidney. their Gestational Ages (GA). A sonogram was done for each in the first trimester where the foetus's Crown Rump Length (CRL) was measured. The pregnant women were selected on the basis of the simple random sampling technique. Consents were taken from them before the study. A thorough history was taken and a complete examination was done. Any woman who had an uncertain GA, under nutrition, obesity or a disease was excluded. The true GA for each case was calculated as the sum of the age at the time of the first sonogram as determined by the CRL plus the number of weeks elapsed between the sonograms as stated by Honarvar et al., [19]. A real-time ultrasound (Medison $\mathrm{X} 8$ with a $0.9 \mathrm{KHz}$ curvilinear transducer, USA) was used to measure the foetal kidney length and the AFI. The Institutional Ethical Committee Approval was obtained prior to the study.

The right foetal kidney length was measured as the maximal longitudinal renal axis; the two calipers were positioned in relation to the upper and lower poles of the kidney Fig. (1) as described by [2]. A regression equation was generated as follows: The predicted $(\mathrm{GA})=\alpha$ (constant $)+\beta \mathrm{X}$ \pm the Standard Error (SE) of estimate in weeks, where $X$ represented the measurement and $\beta$ was the regression coefficient.

The evaluation of the AFI was done with the modified four-quadrant technique. The uterine cavity was divided into four quadrants. The vertical diameter of the largest pocket in each quadrant was measured Fig. (2). The AFI was the sum of those four quadrants according to Hinh and Ladinsky [20]. An AFI chart was obtained expressing the average volume of the amniotic fluid in millimeters based on the gestational age in weeks as suggested by Jeng et al., [21].

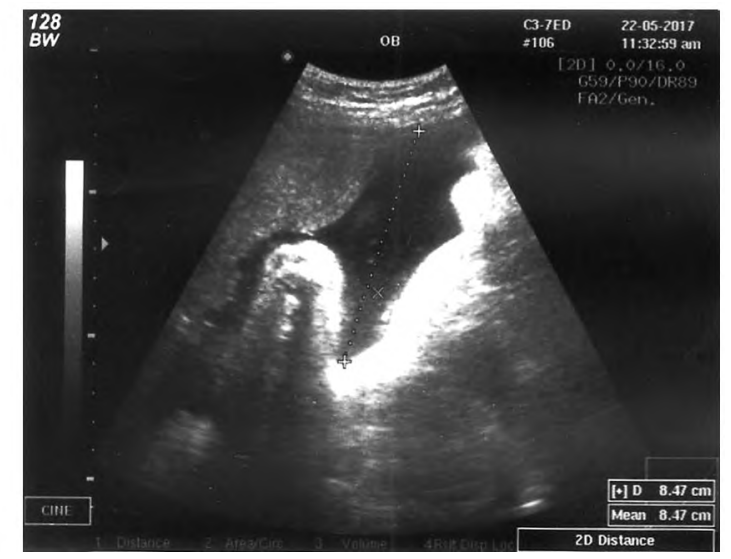

Fig. (2): An ultrasonographic image showing the vertical diameter of the largest pocket in one of the four quadrants. 
Only one professional performed all the examinations in order to avoid the inter-observer variability. The foetal ultrasonographic measurements were grouped into weeks. Statistical analyses were performed with ANOVA, F-test, correlation coefficient and linear regression using SPSS Version 16.0 (SPSS Inc., Chicago, IL, USA) and $p<0.05$ was considered statistically significant.

\section{Results}

The measurements of the foetal kidney lengths were obtained between the 14 th and 42 nd weeks of gestation. The minimum, maximum, mean and Standard Deviation (SD) of the foetal kidney lengths were elicited weekly in (Table 1). The crude values of the means of the foetal kidney lengths \pm 2 SD according to the gestational ages were represented in Chart (1). The 5 th, 50th and $95^{\text {th }}$ percentiles of the foetal kidney lengths according to the gestational ages after being submitted to a smoothing process using the quadratic polynomial adjustments were elicited in Chart (2). The range of the mean \pm SD of the foetal kidney length was from $9.31 \pm 0.19 \mathrm{~mm}$ at the 14 th week to a maximum of $45.22 \pm 0.12 \mathrm{~mm}$ at the $42 \mathrm{nd}$ week of gestation.

There was a significantly strong positive correlation between the gestational age and the foetal kidney length ( $r=0.992, p=0.000$ ). The linear regression equation was: The predicted gestational age $=6.315+0.727 \mathrm{X}$ the foetal kidney length \pm 1.078 (Tables 2,3) \& Chart (3).

As regards the AFI, the minimum, maximum, mean and SD were elicited weekly in (Table 4). The crude values of the means of the AFI \pm 2 SD according to the gestational ages were represented in Chart (4). The 5 th, 50 th and 95 th percentiles of the AFI according to the gestational ages after being submitted to a smoothing process using the quadratic polynomial adjustments were shown in Chart (5). The range of the mean \pm SD of the AFI increased from $118.32 \pm 0.4 \mathrm{~mm}$ at the 14 th week to a maximum of $147.16 \pm 0.09 \mathrm{~mm}$ at the 24 th week of gestation. Then, the mean \pm SD of the AFI took a plateau form from $147.13 \pm 0.08 \mathrm{~mm}$ at the 25 th week to $144.35 \pm 0.24 \mathrm{~mm}$ at the $32 \mathrm{nd}$ week of gestation. Lastly, the mean \pm SD of the AFI decreased from $142.72 \pm 0.33 \mathrm{~mm}$ at the 33 rd week to $110.83 \pm$ $0.47 \mathrm{~mm}$ at the $42 \mathrm{nd}$ week of gestation.

There was a significantly strong positive correlation between the AFI and the gestational age from 14 to 24 weeks ( $r=0.978, p=0.000$ ). The linear regression equation was: The predicted gestational age $=20.740+0.296 \mathrm{X}$ the AFI \pm 0.661 (Tables 6 , 7) \& Chart (6).

There was a significantly strong negative correlation between the gestational age from 33 to 42 weeks and the AFI ( $r=-0.972, p=0.000)$. The linear regression equation was: The predicted gestational age $=71.575-0.261 \mathrm{X}$ the AFI \pm 0.688 (Tables 8 , 9) \& Chart (7).

There was a significantly strong positive correlation between the AFI and the foetal kidney length throughout the gestational ages from 14 to 24 weeks ( $r=0.986, p=0.000$ ). The linear regression equation was: The predicted foetal kidney length= $98.487+2.064 \mathrm{X}$ the AFI \pm 1.735 (Tables 10,11 ) \& Chart (8).

There was a significantly strong negative correlation between the foetal kidney length and the AFI throughout the gestational ages from 33 to 42 weeks $(r=-0.935, p=0.000)$. The linear regression equation was: The predicted foetal kidney length= 354.377 - 5.261 X the AFI \pm 3.841 (Tables 12,13) \& Chart (9).

Table (1): Descriptive statistics of the foetal kidney lengths in $(\mathrm{mm})$ based on the gestational ages in weeks in the normal Upper Egyptian pregnancies.

\begin{tabular}{llccll}
\hline & N & Minimum & Maximum & Mean & SD \\
\hline W14 & 8 & 9.00 & 9.55 & 9.31 & 0.19 \\
W15 & 8 & 10.50 & 11.30 & 10.91 & 0.29 \\
W16 & 8 & 12.00 & 12.80 & 12.45 & 0.26 \\
W17 & 8 & 14.00 & 14.79 & 14.51 & 0.28 \\
W18 & 8 & 15.50 & 16.30 & 15.87 & 0.28 \\
W19 & 8 & 17.50 & 17.99 & 17.77 & 0.16 \\
W20 & 8 & 18.00 & 19.20 & 18.66 & 0.34 \\
W21 & 8 & 20.00 & 22.00 & 20.96 & 0.65 \\
W22 & 8 & 22.50 & 23.10 & 22.83 & 0.21 \\
W23 & 8 & 23.20 & 23.85 & 23.55 & 0.23 \\
W24 & 8 & 23.90 & 24.80 & 24.44 & 0.34 \\
W25 & 8 & 24.85 & 25.70 & 25.27 & 0.36 \\
W26 & 8 & 26.20 & 26.80 & 26.50 & 0.22 \\
W27 & 8 & 27.60 & 28.00 & 27.81 & 0.13 \\
W28 & 8 & 29.80 & 30.80 & 30.47 & 0.37 \\
W29 & 8 & 31.70 & 32.00 & 31.85 & 0.11 \\
W30 & 8 & 33.70 & 34.14 & 33.93 & 0.14 \\
W31 & 8 & 34.20 & 35.72 & 35.12 & 0.70 \\
W32 & 8 & 37.00 & 37.78 & 37.41 & 0.28 \\
W33 & 8 & 38.70 & 39.10 & 38.88 & 0.13 \\
W34 & 8 & 40.50 & 40.80 & 40.66 & 0.10 \\
W35 & 8 & 41.00 & 41.47 & 41.29 & 0.14 \\
W36 & 8 & 41.60 & 42.00 & 41.83 & 0.15 \\
W37 & 8 & 42.20 & 42.59 & 42.38 & 0.12 \\
W38 & 8 & 42.62 & 42.93 & 42.80 & 0.10 \\
W39 & 8 & 42.99 & 43.73 & 43.45 & 0.28 \\
W40 & 8 & 44.00 & 44.68 & 44.44 & 0.22 \\
W41 & 8 & 44.70 & 44.90 & 44.79 & 0.07 \\
W42 & 8 & 45.00 & 45.38 & 45.22 & 0.12 \\
\hline & & & & & \\
\hline
\end{tabular}


Table (2): Correlation between the foetal kidney length and the gestational age.

\begin{tabular}{lccccc}
\hline Model & $r$ & $r$ square & $\begin{array}{c}\text { Adjusted } \\
r \text { square }\end{array}$ & $\begin{array}{c}\text { SE of } \\
\text { the estimate }\end{array}$ & $\begin{array}{c}p \text { - } \\
\text { value }\end{array}$ \\
\hline 1 & 0.992 & 0.984 & 0.983 & 1.078 & 0.000 \\
\hline
\end{tabular}

Table (3): Linear regression analysis of the foetal kidney length to predict the gestational age.

\begin{tabular}{|c|c|c|c|c|c|}
\hline \multirow{2}{*}{ Model } & \multicolumn{2}{|c|}{$\begin{array}{l}\text { Unstandardized } \\
\text { coefficients }\end{array}$} & \multirow{2}{*}{$\frac{\begin{array}{c}\text { Standardized } \\
\text { coefficients }\end{array}}{\text { Beta }}$} & \multirow[t]{2}{*}{$t$} & \multirow{2}{*}{ Sig. } \\
\hline & B & SE & & & \\
\hline - 1 (constant) & 6.315 & 0.198 & 0.992 & 31.889 & 0.000 \\
\hline $\begin{array}{l}\text { - The foetal } \\
\text { kidney length }\end{array}$ & 0.727 & 0.006 & & 117.247 & 0.000 \\
\hline
\end{tabular}

Table (4): Shows a descriptive statistics of the AFI.

\begin{tabular}{lccccc}
\hline & $\mathrm{N}$ & Minimum & Maximum & Mean & SD \\
\hline W14 & 8 & 117.80 & 118.90 & 118.32 & 0.40 \\
W15 & 8 & 119.00 & 119.90 & 119.52 & 0.29 \\
W16 & 8 & 120.90 & 122.50 & 121.65 & 0.52 \\
W17 & 8 & 127.00 & 128.30 & 127.78 & 0.41 \\
W18 & 8 & 133.00 & 133.90 & 133.53 & 0.28 \\
W19 & 8 & 137.00 & 137.80 & 137.43 & 0.26 \\
W20 & 8 & 137.90 & 138.70 & 138.32 & 0.28 \\
W21 & 8 & 143.00 & 143.75 & 143.43 & 0.25 \\
W22 & 8 & 145.00 & 145.51 & 145.30 & 0.18 \\
W23 & 8 & 145.58 & 146.00 & 145.72 & 0.13 \\
W24 & 8 & 147.00 & 147.28 & 147.16 & 0.09 \\
W25 & 8 & 147.00 & 147.24 & 147.13 & 0.08 \\
W26 & 8 & 146.50 & 147.21 & 147.02 & 0.22 \\
W27 & 8 & 146.20 & 147.00 & 146.49 & 0.26 \\
W28 & 8 & 146.00 & 146.80 & 146.22 & 0.24 \\
W29 & 8 & 145.00 & 145.40 & 145.23 & 0.13 \\
W30 & 8 & 144.40 & 145.20 & 144.83 & 0.26 \\
W31 & 8 & 144.00 & 144.70 & 144.35 & 0.24 \\
W32 & 8 & 144.00 & 144.70 & 144.35 & 0.24 \\
W33 & 8 & 142.10 & 143.20 & 142.72 & 0.33 \\
W34 & 8 & 141.00 & 142.40 & 141.70 & 0.48 \\
W35 & 8 & 139.00 & 140.40 & 139.70 & 0.48 \\
W36 & 8 & 137.00 & 138.40 & 137.70 & 0.48 \\
W37 & 8 & 134.00 & 135.80 & 135.03 & 0.59 \\
W38 & 8 & 131.00 & 132.60 & 131.83 & 0.57 \\
W39 & 8 & 125.50 & 127.00 & 126.20 & 0.55 \\
W40 & 8 & 122.00 & 123.50 & 122.82 & 0.46 \\
W41 & 8 & 114.00 & 116.00 & 115.01 & 0.67 \\
W42 & 8 & 110.00 & 111.60 & 110.83 & 0.47 \\
\hline & & & & & \\
\hline
\end{tabular}

Table (6): Correlation between the AFI and the gestational ages from 14 to 24 weeks.

\begin{tabular}{ccccc}
\hline Model & $r$ & $r$ square & Adjusted $r$ square & SE of the estimate \\
\hline 1 & 0.978 & 0.957 & 0.957 & 0.66188 \\
\hline
\end{tabular}

Table (7): Linear regression analysis of the AFI to predict the gestational age from 14 to 24 weeks.

\begin{tabular}{|c|c|c|c|c|c|}
\hline \multirow{2}{*}{ Model } & \multicolumn{2}{|c|}{$\begin{array}{l}\text { Unstandardized } \\
\text { coefficients }\end{array}$} & \multirow{2}{*}{$\frac{\begin{array}{c}\text { Standardized } \\
\text { coefficients }\end{array}}{\text { Beta }}$} & \multirow[t]{2}{*}{$t$} & \multirow[t]{2}{*}{ Sig. } \\
\hline & B & $\mathrm{SE}$ & & & \\
\hline - 1 (constant) & -20.740 & 0.909 & 0.978 & -22.816 & 0.000 \\
\hline $\begin{array}{l}\text { - The means of } \\
\text { the AFI in } \mathrm{mm}\end{array}$ & 0.296 & 0.007 & & 43.849 & 0.000 \\
\hline
\end{tabular}

Table (8): Correlation between the AFI and the gestational ages from 33 to 42 weeks.

\begin{tabular}{ccccc}
\hline Model & $r$ & $r$ square & Adjusted $r$ square & SE of the estimate \\
\hline 1 & -0.972 & 0.944 & 0.943 & 0.688 \\
\hline
\end{tabular}

Table (9): Linear regression analysis of the AFI to predict the gestational ages from 33 to 42 weeks.

\begin{tabular}{|c|c|c|c|c|c|}
\hline \multirow[t]{2}{*}{ Model } & \multicolumn{2}{|c|}{$\begin{array}{l}\text { Unstandardized } \\
\text { coefficients }\end{array}$} & \multirow{2}{*}{$\begin{array}{c}\begin{array}{c}\text { Standardized } \\
\text { coefficients }\end{array} \\
\text { Beta }\end{array}$} & \multirow[t]{2}{*}{$t$} & \multirow[t]{2}{*}{ Sig. } \\
\hline & B & $\mathrm{SE}$ & & & \\
\hline - 1 (constant) & 71.575 & 0.943 & -0.972 & 75.908 & 0.000 \\
\hline $\begin{array}{l}\text { - The means of } \\
\text { the AFI in } \mathrm{mm}\end{array}$ & -0.261 & 0.007 & & -36.259 & 0.000 \\
\hline
\end{tabular}

Table (10): Correlation between the AFI and the foetal kidney length from 14 to 24 weeks.

\begin{tabular}{ccccc}
\hline Model & $r$ & $r$ square & Adjusted $r$ square & SE of the estimate \\
\hline 1 & 0.986 & 0.973 & 0.973 & 1.73556 \\
\hline
\end{tabular}

Table (11): Linear regression analysis of the foetal kidney length to predict the AFI from 14 to 24 weeks.

\begin{tabular}{lccccc}
\hline \multicolumn{7}{c}{$\begin{array}{c}\text { Unstandardized } \\
\text { coefficients }\end{array}$} & $\begin{array}{c}\text { Standardized } \\
\text { coefficients }\end{array}$ & $t$ & Sig. \\
\hline & $\mathrm{B}$ & $\mathrm{SE}$ & Beta & & \\
\hline - 1 (constant) & 98.487 & 0.670 & 0.986 & 147.090 & 0.000 \\
- The means of \\
$\begin{array}{l}\text { The foetal } \\
\text { kidney length } \\
\text { in mm }\end{array}$ & 2.064 & 0.037 & & 55.782 & 0.000 \\
\hline
\end{tabular}

Table (12): Correlation between the foetal kidney length and the AFI from 33 to 42 weeks.

\begin{tabular}{ccccc}
\hline Model & $r$ & $r$ square & Adjusted $r$ square & SE of the estimate \\
\hline 1 & -0.935 & 0.874 & 0.872 & 3.84103 \\
\hline
\end{tabular}

Table (13): Linear regression analysis of the foetal kidney length to predict the AFI from 33 to 42 weeks.

\begin{tabular}{lccccc}
\hline \multicolumn{7}{c}{$\begin{array}{c}\text { Unstandardized } \\
\text { coefficients }\end{array}$} & $\begin{array}{c}\text { Standardized } \\
\text { coefficients }\end{array}$ & $t$ & Sig. \\
\hline B & SE & Beta & & \\
\hline - 1 (constant) & 354.377 & 9.649 & -0.935 & 36.725 & 0.000 \\
- The means of & -5.261 & 0.226 & & -23.239 & 0.000 \\
the foetal & & & & & \\
$\begin{array}{l}\text { kidney length } \\
\text { in mm }\end{array}$ & & & & & \\
\hline
\end{tabular}




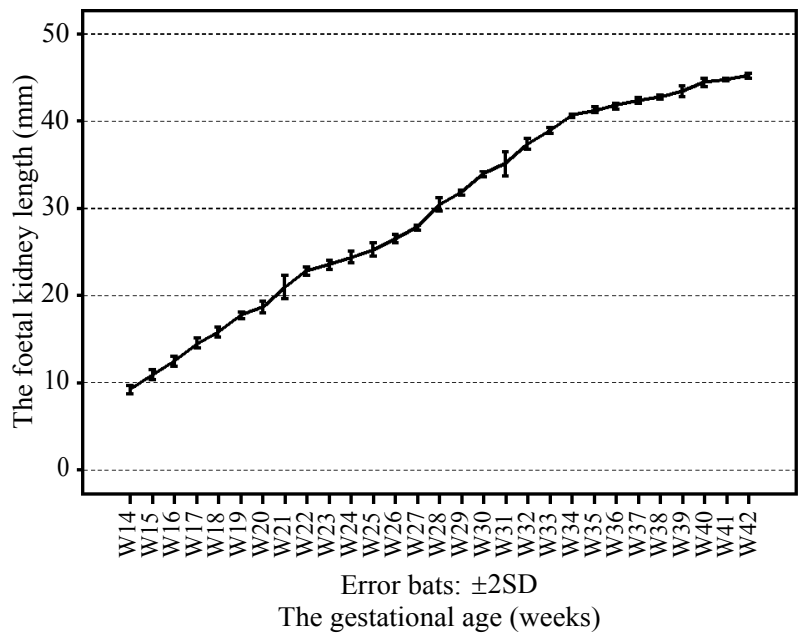

Chart (1): Crude values of the means of the foetal kidney lengths $\pm 2 \mathrm{SD}(\mathrm{mm})$ according to the gestational ages in weeks.

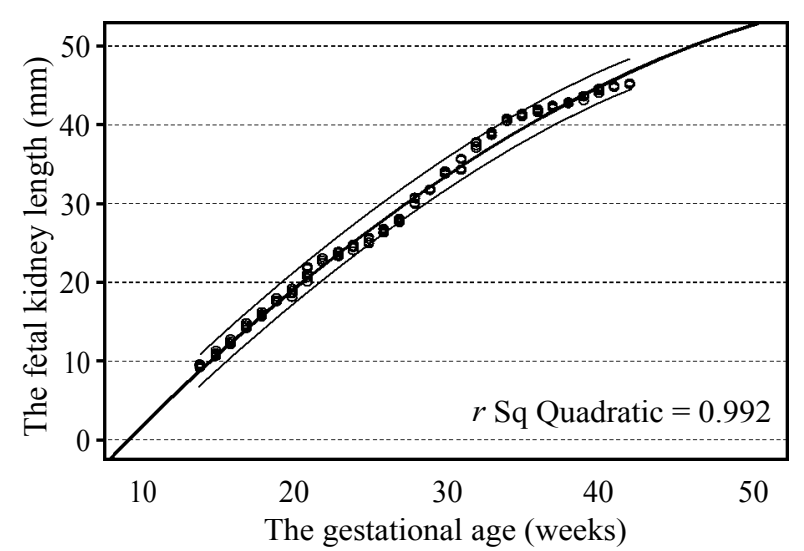

\begin{tabular}{|lll|}
\hline O & $:$ Observer & Middle $-: 50$ th percentile \\
Upper & $: 95$ th percentile & Lower $-: 5$ th percentile
\end{tabular}

Chart (2): 5 th, 50 th and 95 th percentiles of the foetal kidney lengths according to the gestational ages after being submitted to a smoothing process using the quadratic polynomial adjustments.

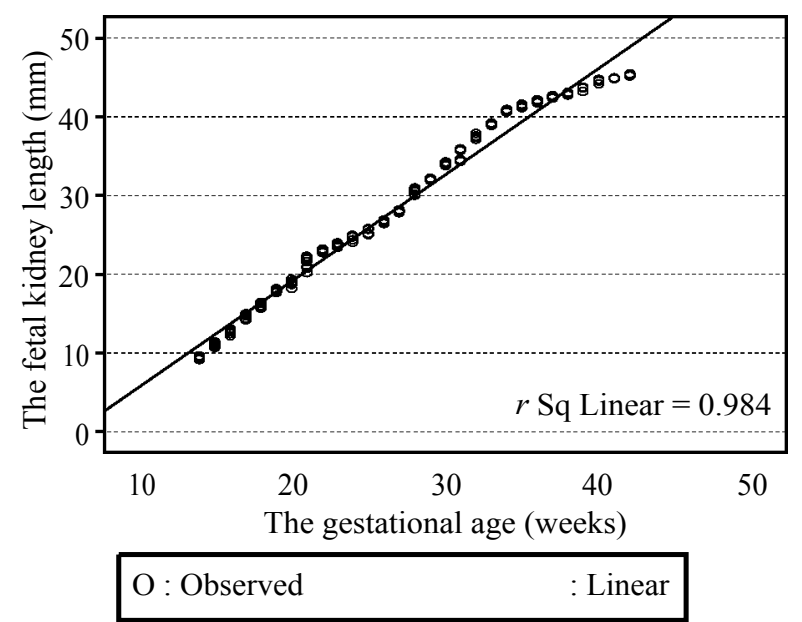

Chart (3): Represents a scatter plot between the gestational age and the foetal kidney length showing the best fit line.

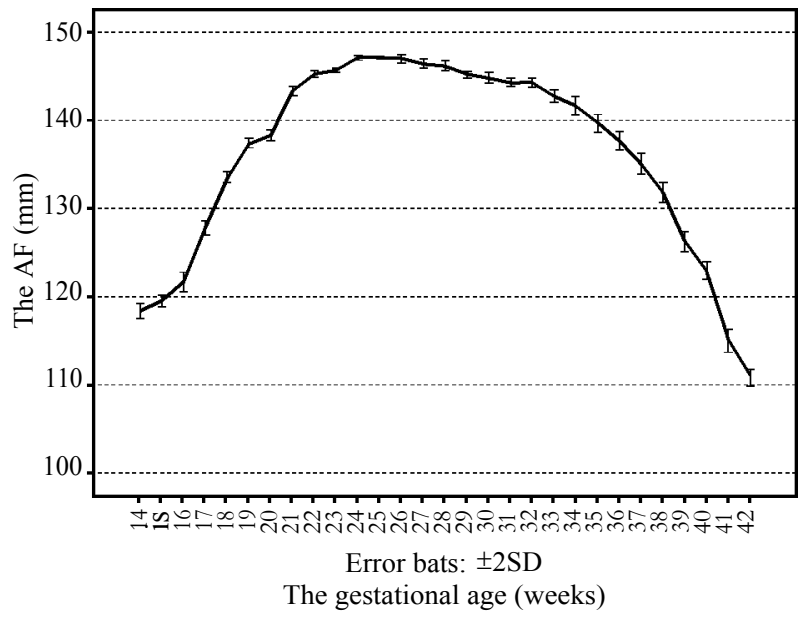

Chart (4): Represents the crude values of the means of the AFI $\pm 2 \mathrm{SD}$ ( $\mathrm{mm}$ ) according to the gestational ages in weeks.

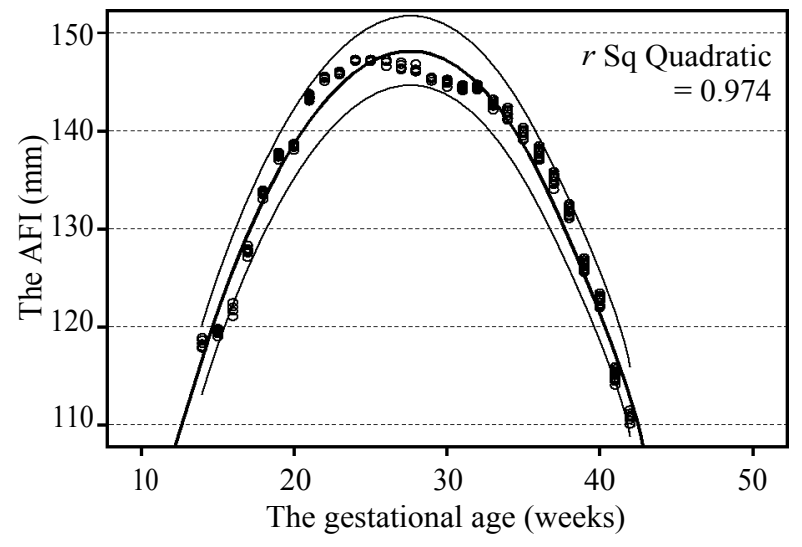

\begin{tabular}{|lll|}
\hline O & $:$ Observer & Middle $-: 50^{\text {th }}$ percentile \\
Upper & $: 95$ th percentile & Lower $-: 5$ th percentile
\end{tabular}

Chart (5): Represents the 5 th, 50 th and 95 th percentiles of the AFI according to the gestational ages after being submitted to a smoothing process using the quadratic polynomial adjustments.

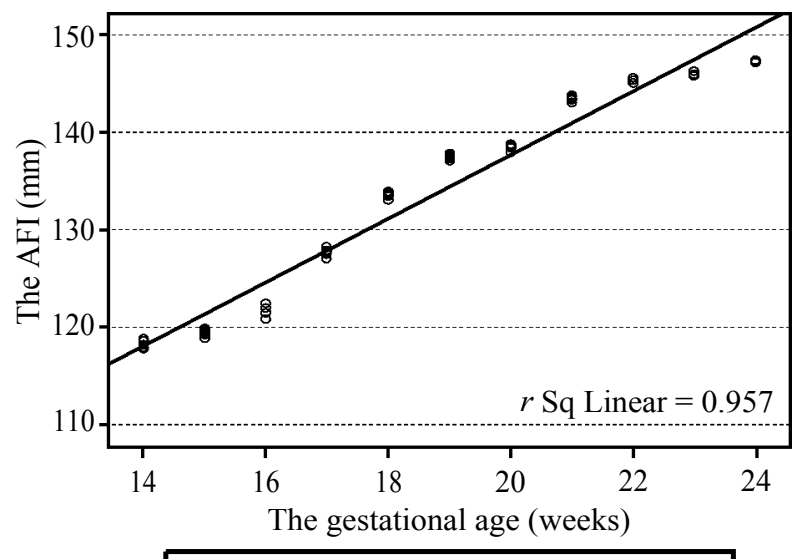

O : Observed : Linear

Chart (6): Represents a scatter plot between the gestational ages from 14 to 24 weeks and the AFI showing the best fit line. 


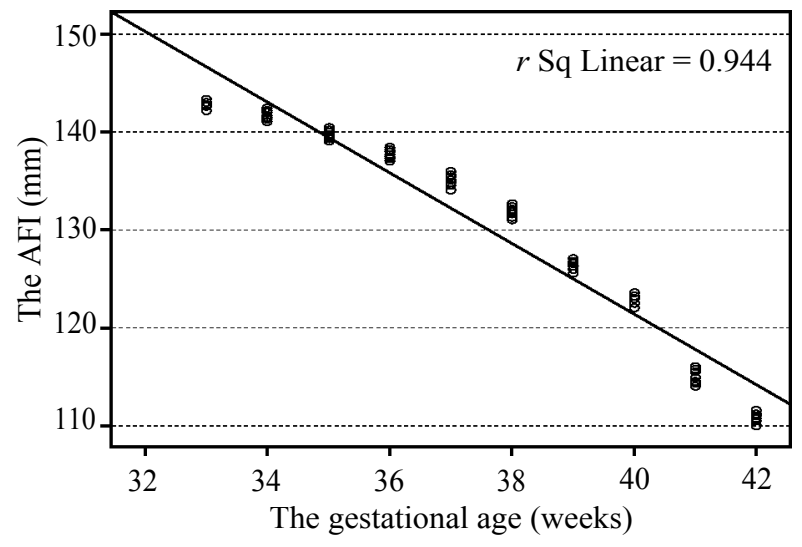

O : Observed

: Linear

Chart (7): Represents a scatter plot between the gestational ages from 32 to 42 weeks and the AFI showing the best fit line.

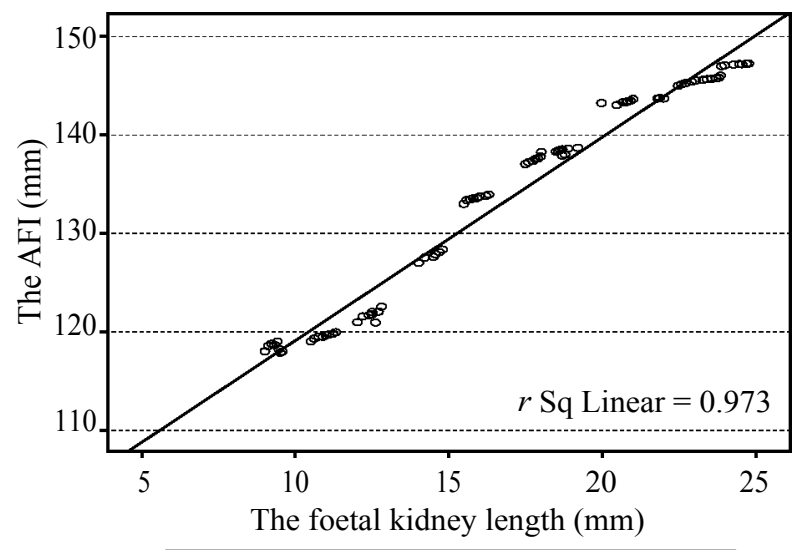

$$
\text { O : Observed : Linear }
$$

Chart (8): Represents a scatter plot between the foetal kidney length and the AFI from 14 to 24 weeks showing the best fit line.

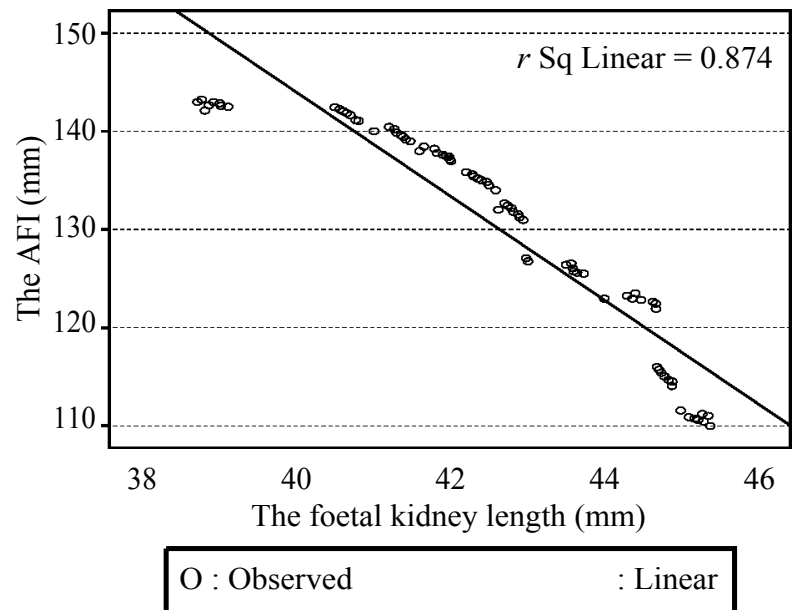

Chart (9): Represents a scatter plot between the foetal kidney length and the AFI from 33 to 42 weeks showing the best fit line.

\section{Discussion}

The present study dealt with the foetal kidney length as a parameter because the foetal growth variation affected all the organs including the anterio-posterior and transverse dimensions of the kidney; however its length remained more or less unaffected as declared by Konje et al., [22] and Toosi and Rezaie-Delui [23]. Witzani and others [24] suggested that the foetal kidney length measurements obtained by the MRI were close to those obtained by the ultrasonography. Gupta and coworkers [25] and Chatterjee et al., [26] reported that the foetal kidney length had a strong correlation with the gestational age in the late trimesters even in the intrauterine growth retardation fetuses.

The present work showed that the range of the mean foetal right kidney length was from $9.31 \mathrm{~mm}$ at the 14 th week to a maximum of $45.22 \mathrm{~mm}$ at the 42 nd week of gestation. There was a uniform increase in its length of an approximately $1 \mathrm{~mm}$ every week which comes in agreement with the result of Bertagnoli et al., [27] and Bardhan et al., [28]. They observed that the renal length in millimeters at any given gestational age was nearly corresponding to the gestational age in weeks and suggested a rule of thumb that was the renal length in millimeters approximated the gestational age in weeks. Hence, the foetal kidney length could be a fascinating tool in the determination of the gestational age without using any software as reported by Kaul et al., [29] and Kumar et al., [30]

An accurate estimation of the foetal age has clinical implications principally in the management of the high risk pregnancies [31,32] .

The present study revealed a significantly strong positive correlation between the gestational age and the foetal kidney length. This comes in agreement with Ahmadi et al., [2] in Iran, Bardhan et al., [28] in India and Ugur et al., [33] among Turkish.

They added that in the cases of the engaged foetal head, that finding proved its worth, where it was difficult to measure the BPD and $\mathrm{HC}$ as well as in the cases of intrauterine growth retardation, macrosomia and malformation where the AC measurement gave false values.

The present work exhibited that the best fit line was with the linear regression equation of: The predicted gestational age from the kidney length $=6.315+0.727 \mathrm{X}$ the foetal kidney length \pm 1.078 . The present finding agrees more or less with Chatterjee et al., [26] and Saxena et al., [5] who reported that the foetal kidney length among Indians could 
be used as an individual parameter in estimating the gestational age, especially in the later trimesters, where the biometric indices might not be much reliable.

Moreover, Goyal et al., [34] reported that among Indians, the foetal kidney could be seen easily sonographically at the 16 th gestational week. They added that the FL was the most accurate single parameter followed by the foetal kidney length. The BPD was the least accurate one. The standard errors were $\pm 7.95, \pm 9.56$ and \pm 9.86 days, respectively. They concluded that the foetal kidney length could be used alone or easily incorporated into the model for dating pregnancies after the 16 th week of gestation, especially when the BPD and FL were difficult to be measured.

The present work revealed that the range of the mean \pm the SD of the AFI increased from 118.32 \pm $0.4 \mathrm{~mm}$ at the 14 th week to a maximum of $147.16 \pm$ $0.09 \mathrm{~mm}$ at the 24 th week of gestation. Then, the mean \pm SD of the AFI took a plateau form from $147.13 \pm 0.08 \mathrm{~mm}$ at the 25 th week to $144.35 \pm 0.24$ $\mathrm{mm}$ at the $32 \mathrm{nd}$ week of gestation. Lastly, the mean \pm SD of the AFI decreased from $142.72 \pm 0.33 \mathrm{~mm}$ at the $33 \mathrm{rd}$ week to $110.83 \pm 0.47 \mathrm{~mm}$ at the $42 \mathrm{nd}$ week of gestation. Although Hebbar et al., [35] in India recorded different means $\pm \mathrm{SD}$ of the AFI values starting from the $34^{\text {th }}$ week to the $39^{\text {th }}$ week of gestation, they coincided with the decreasing values observed in the present work.

This finding comes in agreement with that of Brace [36] who stated that the mechanism of the amniotic fluid production, consumption, composition and volume depended on the gestational age. Fernando [37] reported that the amniotic fluid volume at any time was a balance between the production and consumption. During the first trimester, the major source of the amniotic fluid was the maternal blood and the secretion from the amnion. He observed that it increased rapidly in the first half of pregnancy then it increased slowly till the 37 th week. Thereafter, it declined gradually till the 42 nd week. Dutta [38] added that the study of the amniotic fluid provided useful information about the foetal well-being and maturity.

Jeng et al., [21] in Taiwan found that from 13 weeks' gestation, the AFI increased progressively until 26 weeks. From then to 38 weeks, the AFI measurements demonstrated a little variation. After 38 weeks, the AFI declined gradually towards term. They attributed that reduction to the decreased lung secretions as the baby approached term.
However, doubts remain concerning the normal values of the AFI for each gestational age as stated by Machado et al., [39]. They demonstrated that new data were needed; using reliable reference low-risk pregnant women samples, to establish the AFI limits that would indicate the perinatal risks. They confirmed that some existing curves were based on relatively small sample sizes and a normal AFI for each gestational age was not yet definitely established. Moreover, Lei and Wen [40]-the authors of a Chinese curve-suggested that different normality reference curves were needed to establish the AFI in the different populations.

The present study indicated that there was a significantly strong positive correlation between the AFI and the gestational age from 14 to 24 weeks ( $r=0.978, p=0.000)$. The best fit line was with a linear regression equation of: The predicted gestational age $=-20.740+0.296 \mathrm{X}$ the AFI \pm 0.661 . There was a significantly strong negative correlation between the gestational age from 33 to 42 weeks and the AFI ( $r=-0.972, p=0.000)$. The best fit line was with a linear regression equation of: The predicted gestational age $=71.575-0.261 \mathrm{X}$ the AFI \pm 0.688 .

Kofinas and Kofinas [41] in the USA observed that in the normal pregnancy, the AFI mean was $14.0 \mathrm{~cm}$ at 27 weeks and decreased to $11.4 \mathrm{~cm}$ at 42 weeks $(r=-0.25, p=0.000)$.

Araujo et al., [42] reported that the mean AFI in a Brazilian population ranged from $12.2 \pm 2.6 \mathrm{~cm}$ at 18 weeks to $11.6 \pm 6.0 \mathrm{~cm}$ at 38 weeks of pregnancy. The correlation between the AFI and the GA was best represented by a linear equation of: The AFI $=17.78-0.153 \mathrm{X}$ the GA.

Peixoto et al., [43] introduced reference values for the AFI from the 26 th week to the 42 nd week of gestation in a low-risk Brazilian population. They stated that the mean of the AFI ranged from $14.0 \pm 4.1 \mathrm{~cm}$ at the 26 th week to $8.3 \pm 4.7 \mathrm{~cm}$ at the $42 \mathrm{nd}$ week, respectively. The best linear regression equation for the results' representation was: The AFI $=16.29-0.125 \mathrm{X}$ the GA. Ugur et al., [33] found a moderately negative correlation between the GA and the AFI ( $r=0.499)$ after 24 weeks of pregnancy in the Turkish.

Porter et al., [44] in the USA during a study on two hundred eighty-two uncomplicated sets of twins between 25.5 and 40.5 weeks' gestation found the regression equation relating the median AFI to the gestational age was: The AFI=19.4 - $0.12 \mathrm{X}$ the gestational age. 
The differences between the obtained data in the present study and the other authers' results could be attributed to the variability in the tested gestational age groups and/or populations. The differences in the used ultrasonographic devices and the observers' bias might play a role.

The present study introduced charts for the 5 th, 50th and $95^{\text {th }}$ percentiles of the foetal kidney length and the AFI according to the gestational age after being submitted to a smoothing process using the quadratic polynomial adjustments. The importance of such curves was due to their greater capacity to identify abnormal cases as mentioned by Machado et al., [39]. They mentioned that if the 5 th percentile was used as the lower normal limit, then there would be a less likelihood of missing a case of areal oligohydramnios.

The present study exhibited that there was a significantly strong positive correlation between the AFI and the foetal kidney length from 14 to 24 weeks of gestation ( $r=0.986, p=0.000)$. The best fit line was with a linear regression equation of: The predicted gestational age $=98.487+2.064 \mathrm{X}$ the AFI \pm 1.735 . On the other hand, there was a significantly strong negative correlation between the foetal kidney length and the AFI from 33 to 42 weeks of gestational ( $r=-0.935, p=0.000$ ). The best fit line was with a linear regression equation of: The predicted AFI=354.377 5.261 X the foetal kidney length \pm 3.841 . According to the available literature, no previous research discussed the correlation between the AFI and the foetal kidney length as early as the second trimester of pregnancy.

\section{Conclusion:}

The present work establishes reference values for both the foetal kidney length and AFI in the normal Upper Egyptian pregnancies. It also exhibits the correlation between the foetal kidney length and AFI as early as the second trimester of pregnancy. Therefore, the obtained data could be useful in the prediction of a variety of abnormalities and in the assessment of the gestational age when the date of conception is uncertain.

\section{References}

1- VAN VUUREN S., DAMEN-ELIAS H., STIGTER R., et al.: Foetalkidney, renal pelvis and adrenal gland nomograms. Ultrasound in Obstetrics and Gynecology, 40: 65964, 2012.

2- AHMADI F., DIZAJ A., AKHBARI F., et al.: Foetalkidney Measurement in 26-39 Weeks Gestation in Normal Fetuses of Iranian Pregnant Women. Journal of Pregnancy and Child Health, 2: 2-5, 2015.
3- YUSUF N., MOSLEM F. and HAQUE J.: Foetal Kidney Length: Can be a Nęw Parameter for Determination of Gestational Age in ${ }^{3 r d}$ Trimester. Journal of Teachers Association, 20 (2): 147-50, 2007.

4- BUTT K. and LIM K.: Society of Obstetricians and Gynecologists of Canada. Determination of gestational age by ultrasound. International Journal of Gynecology and Obstetrics, 36: 171-83, 2014.

5- SAXENA R., SAXENA G., JOSHI K., et al.: Foetal Kidney Length for Determination of Gestational Age in Pregnancy by Ultrasonography. International Journal of Medical Research Professional, 2 (6): 71-3, 2016.

6- FILLY P.A. and FELDSTEIN V.A.: Ultrasound Evaluation of normal foetal anatomy. In: Callen PW, editor. Ultrasonography in obstetrics and gynecology. 5 th ed. Philadelphia: Saunders, 342-3, 2007.

7- KANSARIA J. and PARULEKAR S.: Nomogram for foetal kidney length. Bombay Hospital Journal, 51: 15562, 2009.

8- GARG A., GOYAL N., GOREA R., et al.: Nomogram from foetal kidney length by ultrasonographically. Journal of Punjab Academy of Forensic Medicine \& Toxicology, 15: 14-6, 2015.

9- PETER M., NAYAK A., GIRI P. and JAIN M.: Foetalkidney length as a parameter for determination of gestational age from 20 th week to term in healthy women with uncomplicated pregnancy International Journal of Research in Medical Sciences, 5 (5): 1869-73, 2017.

10- GRIFFIN M., ATTILAKOS G., GREENWOOD R. and DENBOW M.: Amniotic fluid index in low-risk, postdates pregnancies. Foetal Diagnostic Therapy, 26 (4): 212-5, 2009.

11- ASGHARNIA M., FARAJI R., SALAMAT F., et al.: Perinatal outcomes of pregnancies with borderline versus normal amniotic fluid index. Iran Journal of Reproductive Medicine, 11 (9): 705-10, 2013.

12- ALI S.: Assessment of amniotic fluid index in normal pregnancy at a tertiary care hospital setting. Journal of Ayub Medical College Abbottabad, 21: 149-51, 2009.

13- UNDERWOOD A., GILBERT W. and SHERMAN M.: Amniotic Fluid: Not Just Foetal Urine Anymore. Journal of Perinatology, 25: 341-8, 2005.

14- BORGES V., ROSOSCHANSKY J., ABBADE J., et al.: Effect of maternal hydration on the increase of amniotic fluid index. Brazilian Journal of Medical and Biological Research, 44: 263-6, 2011.

15- SYEDA A.T., ASHWINI K., MUHAMMAD K.A. and FARQUANA Q.: A Study of Amniotic Fluid Index in Term Pregnancy. International Journal of Current Research and Academic Review, 2: 147-52, 2014.

16- STIGER R., MULDER E., BRUINSE H. and VISSER G.: Foetal urine production in late pregnancy. Obstetrics and Gynecology, 2011: 1-6, 2011.

17- PRI-PAZ S., KHALEK N., FUCHS K. and SIMPSON L.: Maximal amniotic fluid index as a prognostic factor in pregnancies complicated by polyhydramnios. Ultrasound in Obstetrics and Gynecology, 39: 648-53, 2012.

18- PATRELLI T.S., GIZZO S., COSMI E., et al.: Maternal hydration therapy improves the quantity of amniotic fluid 
and the pregnancy outcome in third-trimester isolated oligohydramnios: A controlled randomized institutional trial. Journal of Ultrasound Medicine, 31 (2): 239-44, 2012.

19- HONARVAR U.M., ALLAHYARI M. and DEHBASHI S.: Assessment of gestational age based on ultrasonic femur length after the first trimester: A simple mathematical correlation between Gestational Age (GA)/and Femur Length (FL). International Journal of Gynecology \& Obstetrics, 70: 335-40, 2000.

20- HINH N.D. and LADINSKY J.L.: Amniotic fluid index measurements in normal pregnancy after 28 gestational weeks. International Journal of Gynecology and Obstetrics, 91 (2): 132-6, 2005.

21- JENG C.J., JOU T.J., WANG K.G., et al.: Amniotic fluid index measurement with the four-quadrant technique during pregnancy. Journal of Reproductive Medicine, 35 (7): 674-7, 1990.

22- KONJE J.C., BELL S.C., MORTON J.J., et al.: Human foetal kidney morphometry during gestation and the relationship between weight, kidney morphometry and plasma active remain concentration as birth. Clinical Science, 91: 169-75, 1996.

23- TOOSI F. and REZAIE-DELUI H.: Evaluation of the Normal Foetal Kidney Length and Its Correlation with Gestational Age. Acta Medica Iranica, 51 (5): 303-6, 2013.

24- WITZANI L., CHRISTIAN P., MARCUS H., et al.: Normal renal development investigated with foetal MRI European Journal of Radiology, 57: 294-302, 2006.

25- GUPTA D.P., GUPTA H.P. and ZAIDI Z.: Accuracy in Estimation of Gestational Age in Third Trimester by Foetal Kidney Length in Indian women. Indian Journal of Clinical Practice, 24 (5): 459-63, 2013.

26- CHATTERJEE S., YADAV K., PRAKASH P. and SHEKHAWAT K.: Foetal kidney length as a parameter for determination of gestational age in pregnancy by ultrasonography. International Journal of Reproduction, Contraception, Obstetrics and Gynecology, 5 (6): 1949-52, 2016.

27- BERTAGNOLI L., LALATTA F. and GALLICCHIO R.: Quantitative characterization of the growth of the foetal kidney. Journal of Clinical Ultrasound, 11: 349-56, 1983.

28- BARDHAN J., GHOSH S.K., SARKAR K.N. and SARKAR M.: Foetal kidney length as a parameter for gestational age determination and its comparative evaluation with other foetal biometric indices. International Archives of Integrated Medicine, 3 (8): 36-44, 2016.

29- KAUL I., MENIA V. and ANAND A.K.: Role of Foetal Kidney Length in Estimation of Gestational Age. Journal of Medical Education \& Research, 14 (2): 65-9, 2012.

30- KUMAR K., LALWANI R. and BABU R.: Ultrasonographic estimation of foetal gestational age by foetal kidney length. Journal of the Anatomical society of India, 62: 33-6, 2013.

31- PERNOLL M.L. and TAYLOR C.M.: Normal pregnancy and prenatal care. In: Decherney A.H., Pernoll M.L. (eds).
Current Obstetric and Gynecologic Diagnosis and Treatment. 8th edition. Fast Norwalk: Appleton and Lange, pp. 183-201, 1994.

32- SHIVALINGAIAH N., SOWMYA and ANANYA K.R.: Foetal kidney length as a parameter for determination of gestational age in pregnancy. International Journal of Reproduction, Contraception, Obstetrics and Gynecology, 3 (2): 424-7, 2014.

33- UGUR M., MUSTAFA A., OZCAN H., et al.: Foetal kidney length as a useful adjunct parameter for better determination of gestational age. Saudi Medical Journal, 37 (5): 533-7, 2016.

34- GOYAL L., AGARWAL S., CHANDRA S., et al.: Foetal Kidney Length: A Useful Parameter For Ultrasonographic Gestational Age Calculation. National Journal of Integrated Research Medicine, 7 (1): 55-8, 2016.

35- HEBBAR S., RAI L., ADIGA P. and GURUVARE S. Reference Ranges of Amniotic Fluid Index in Late Third Trimester of Pregnancy: What Should the Optimal Interval between Two Ultrasound Examinations Be? Journal of Pregnancy, 5: 1-7, 2015.

36- BRACE R.A.: Physiology of amniotic fluid volume regulation. Clinical Obstetrics and Gynaecology LippincotRaven Publication, 40 (2): 280-9, 1997.

37- FERNANDO A.: Practical guide to high risk pregnancy and delivery. 2nd ed. Mosby Year Book, 413-29, 1993.

38- DUTTA D.C.: The placenta and the membranes. In: Text book of obstetrics and gynaecology including perinatology and contraception. The 6 th ed. New central book agency, Calcutta, India, 38-9, 2004.

39- MACHADO M., CECATTI J., KRUPA F. and FAUNDES A.: Curve of amniotic fluid index measurements in lowrisk pregnancy. Acta Obstetricia et Gynecologica, 86: 37 41, 2007.

40- LEI H. and WEN S.: Normal amniotic fluid index by gestational week in a Chinese population. Obstetrics and Gynecology, 92: 237-40, 1998.

41- KOFINAS A. and KOFINAS G.: Differences in amniotic fluid patterns and foetal biometric parameters in third trimester pregnancies with and without diabetes. Journal of Maternal Foetal Neonatal Medicine, 19 (10): 633-8, 2006.

42- ARAUJO E., MARTINS P., PARES B., et al.: Reference range for amniotic fluid index measurements in a Brazilian population. Journal of Perinatal Medicine, 42 (4): 535 9, 2014.

43- PEIXOTO A., CALDAS T., MARTINS W., et al.: Unconditional reference values for the amniotic fluid index measurement between $26 \mathrm{w} 0 \mathrm{~d}$ and $41 \mathrm{w} 6 \mathrm{~d}$ of gestation in low-risk pregnancies. Journal of Maternal Foetal Neonatal Medicine, 29 (20): 3243-8, 2016.

44- PORTER T., DILDY G., BLANCHARD J., et al.: Normal values for amniotic fluid index during uncomplicated twin pregnancy. Obstetrics and Gynecology, 87 (5): 699 702,1996 


\section{نمو كلية الجنين وتكوين السائل الآمنيوسى في فمي

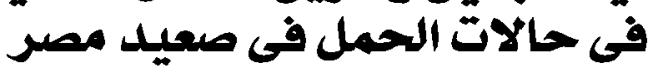

مقدمة: إن نمو كلية الجنين مهم لآداء وظيفتها الطبيعية. يستخدم مؤشر السائل الآمنيوسى لتقدير حجم السائل الآمينوسى والمصدر الرئيسى له هو بول الجنين.

الهدف من الدراسة: إنشاء قيم مرجعية لطقل كلية الجنين ومؤثر السائل الآمنيوسى خلال الثثين الثانى والثالث من الممل فى حالات

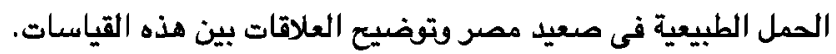

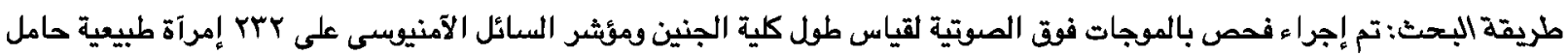

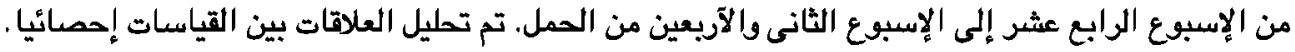

النتائج : زاد طول كلية الجنين تدريجيا مع تقدم الحمل وكان هناك إرتباط معنوى إيجابى بين طول كلية الجنين وعمر الحمل. وآظهر الإنحدار

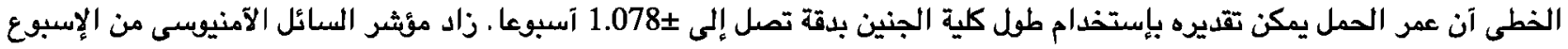

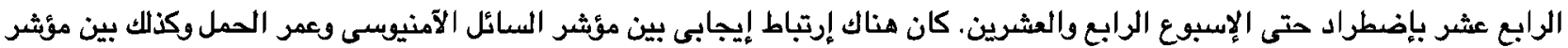

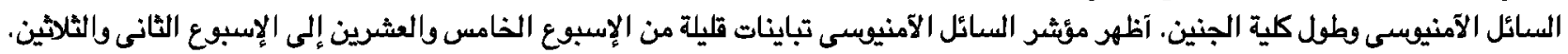

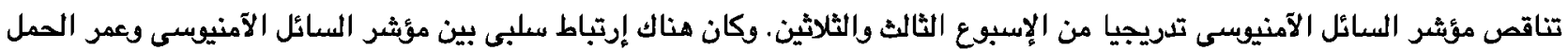
وبين مؤشر السائل الآمنيوسي وطول كلية الجنين.

الخلاصة: تقدم هذه الدراسة قيم مرجعية لكل من طهل كلية الجنين ومؤشر السائل الآمنيسى فى حالات الحمل الطبيعية فى صعيد مصر. كما تتاقش العلاقة بين طول كلية الجنين ومؤشر السائل الآمنيوسى من الثلث الثانى من الحمل، في البداية تكون علاقة طردية، ثم تظهر تباينات

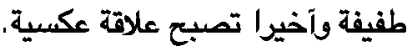

